\title{
Els textos de ciència tenen ideologia
}

\author{
Conxita Márquez, Àngels Prat i Anna Marbà \\ Facultat de Ciències de l'Educació, UAB \\ Conxita.Marquez@uab.es
}

En aquest article es planteja la importància de formar una ciutadania capaç de llegir críticament els textos de contingut científic i la necessitat de desenvolupar, des de la classe de ciències, activitats per afavorir aquesta competència. Proposar la lectura de notícies de premsa, de textos divulgatius i d'anuncis publicitaris des de la perspectiva de la lectura crítica permetrà que l'alumnat reconegui la ideologia d'aquests documents i desenvolupar els mecanismes per interpretar-la.

Paraules clau: lectura crítica, textos de ciències, premsa, competència científica

Ningú no posa en dubte la necessitat que des del sistema educatiu es contribueixi a la formació de ciutadans i ciutadanes capacitats per la convivència en un món plural, democràtic, lliure, amb riscos, però també amb avantatges sense precedents. Aquest objectiu s'ha concretat en un nou currículum que promou l'adquisició de les competències bàsiques en l'educació obligatòria.

En aquest nou marc curricular creiem que les Ciències de la Naturalesa hi tenen un paper rellevant en la mesura que la seva finalitat és capacitar als estudiants per accedir als coneixements científics que els possibilitin la comprensió dels fenòmens del món i actuar de manera responsable i crítica. Però l'escola d'avui no pot ensenyar la ciència del demà i, per tant, cal que ajudem l'alumnat a desenvolupar estratègies que el facin capaç de seguir aprenent més enllà de l'escola.

De la varietat d'activitats que cal promoure a les classes de ciències voldríem destacar les relacionades amb la lectura, ja que una comprensió lectora eficaç pot facilitar el procés d'adquirir, modificar i aplicar els coneixements científics en el període escolar i al llarg de tota al vida. També voldríem incidir en la necessitat de plantejar l'activitat lectora des d'una perspectiva sociocultural i acceptar, entre altres consideracions, que els textos científics també tenen intenció i ideologia (Cassany, 2008).

Ara bé, formar persones interessades per la ciència, aconseguir lectors competents, o millor, ciu- tadans lectors (Da Silva i Almeida, 1998), comporta canvis en els documents que s'utilitzen a les classes i en la manera de gestionar-los (Márquez i Prat, 2005).

\section{Quins textos llegir?}

Hi ha una gran diversitat de textos i documents (articles, editorials, llibres especialitzats, publicitat, reportatges, documentals, cartes al director, televisió, radio, i Internet) a través dels quals se'ns informa de quins són els temes d'interès o de preocupació de la societat i també quins són els àmbits d'estudi i recerca de la comunitat científica. Aquests textos són sovint d'una complexitat elevada i comprendre'ls no significa només ser capaços d'identificar les idees principals o de resumir-los: comporta també, des de la perspectiva de lectura crítica, reconèixer-ne la intenció i la ideologia (qui I'ha escrit, per a què l'ha escrit, en quin context, etc.), l'estatus de les afirmacions científiques que hi apareixen (identificar si allò que es diu és una hipòtesi, una afirmació, una conclusió, una evidència, etc...) i poder donar l'opinió personal fonamentada en les nostres conviccions i sobretot en els coneixements.

Si davant un text periodístic o publicitari plantegem a l'alumnat que identifiqui la funció de les afirmacions que hi apareixen, veurem la gran dificultat 
que tenen en diferenciar, per exemple, evidències d'especulacions o de prediccions (Prat, Márquez i Marbà, 2008; Oliveras i Sanmartí, 2008). I creiem que ser capaç de fer aquestes distincions és important per valorar la qualitat de la informació aportada pel text.

Els articles de divulgació científica, les notícies de premsa, els documents que obtenim en una cerca a Internet, etc. han de tenir el seu Iloc a la classe de ciències i mai no s'hauria de renunciar a un text interessant perquè el nivell de dificultat sigui molt alt. En aquests casos, es pot optar per alternar propostes de lectura col-lectiva, individual i en grups reduïts per tal d'estimular i afavorir les interaccions entre els alumnes que permetin una millor comprensió lectora del text.

Escollir per part del professorat un text determinat no hauria de pretendre fer alumnes especialistes en el tema, sinó facilitar la connexió d'allò que s'estudia a classe amb temes d'actualitat, o a l'inrevés. Per exemple, la lectura d'una notícia de diari que parli de la dificultat creixent en la reproducció humana, tant en humans com en animals a causa de factors ambientals, permet que l'alumnat reconegui la pontencialitat de les idees científiques plantejades a l'aula -identificant els factors ambientals com a estímuls i les dificultats reproductives com a resposta- per comprendre situacions que per la seva actualitat són presents en els mitjans de comunicació.

Evidentment, aquests textos permeten treballar els aspectes ètics i socials de temàtiques científiques, com per exemple el cas del dopatge en els esportistes d'elit. En aquest cas, més enllà d'entendre l'efecte de l'EPO sobre l'organisme, cal valorar els aspectes que porten els esportistes d'elit -i a molts d'altres- a consumir substàncies per incrementar el seu rendiment. Per altra banda ens fa plantejar la part positiva d'aquesta substància: la capacitat d'estimular la producció d'eritròcits en pacients amb anèmies extremes i com pot millorar la seva qualitat de vida.

\section{L'ús de premsa a l'aula de ciències}

La incorporació de notícies de premsa actuals i de documents divulgatius, ens fa avinent la lectura crítica.

Una de les principals diferències d'utilizar textos periodístics o publicitaris envers el llibre de text convencional és la possibilitat que ens ofereix de treballar el qüestionament de l'autoria. A l'aula, l'alumnat no acostuma a plantejar-se qui ha escrit el text, o amb quina intenció l'escriu. En canvi, quan es llegeix premsa escrita és de vital importàn- cia poder reconèixer qui i amb quin interès escriu aquell text. En aquest sentit, resulta molt interessant fer pensar l'alumnat si creu que la notícia que s'està llegint l'ha escrita un periodista o un científic i diferenciar quines parts del text corresponen a afirmacions contrastades i quines són opinions o especulacions de l'autor.

La premsa escrita, i especialment la de caire més publicitari, pot promoure -i ho hauria de fer- la capacitat de valorar si les dades que es presenten són les necessàries per justificar l'eficàcia del producte que s'està anunciant. Aquesta reflexió és pertinent en l'època actual en què el terme testat científicament és sinònim de qualitat i eficàcia. Així doncs, a l'aula, podem discutir la fiabilitat, o els límits, dels tests de consumidors o la significativitat de la mostra estudiada.

Un altre aspecte sensible de ser analitzat és la idoneïtat dels productes que presenten. Així, per exemple, es pot buscar informació sobre les substàncies anunciades, per exemple, en cremes cosmètiques. Un dels entrebancs és la impossibilitat d'esbrinar quina és la seva composició química i, per tant, comporta dificultat per valorar-ne el seu efecte. Tot i això, a partir de conèixer com està estructurada l'epidermis i com funcionen les cèl-lules, es podran discutir els suposats efectes miraculosos d'algunes substàncies. Si identifiquem que una de les més usades actualment per fer desaparèixer les línies d'expressió de la cara és el bòtox, sabrem que aquesta substància és una de les toxines del bacteri Clostridium botulinum causant del botulisme, una toxina capaç d'entrar en determinats axons neuronals i provocar la paralització del nervi. Si tenim aquesta informació i coneixem la capacitat de les cèl-lules per intercanviar matèria i energia, sabrem justificar la durada de l'efecte del bòtox relacionada amb la capacitat de la neurona de metabolitzar-la. També anticiparem així els possibles efectes no desitjats relacionats amb la seva funció biològica, com pot ser la paràlisi muscular.

Els anuncis fan evidents i posen a debat els imaginaris collectius, els cànons estètics del moment, pel que fa a bellesa, moda, vida sana, ecologia, models socials... tots relacionats directament amb la felicitat, la salut i el triomf personal. Només volem mostrar alguns exemples de binomis i les seves contradiccions: tenim la tendència a entendre que un ritme de vida estressant és sinònim de triomf social, que l'alimentació ecològica amb llet amb substàncies actives 0 amb llet de vaques alimentades amb transgènics pot reduir el colesterol. Proposem reflexionar sobre alguns imaginaris que hi ha darrera les notícies i especialment en publicitat: un cas paradigmàtic $i$ ben actual fa referència $a$ la profusió de productes làctics enriquits. Una pers- 
pectiva científica ens hauria de fer qüestionar si és millor aquesta llet, si tenim necessitat de prendre aquests productes complementaris i què aporten $\mathrm{a}$ l'organisme.

\section{I per acabar}

Els articles, editorials, llibres especialitzats, publicitat, reportatges, cartes al director, televisió, radio, Internet, etc... no són llibres de text. Com a molt els poden considerar com "llibres de text amb vida" que ajuden a salvar la distància que de vegades hi ha entre el currículum que es treballa a la classe i el que passa al món real. Aquests documents són només una font d'informació sobre el coneixement i l'activitat científica que sovint caldria contrastar amb altres fonts. Són documents, però, que tenen un propòsit que pot ser informar, interpretar, persuadir, entretenir, opinar, etc.

Per tant, és important que l'alumnat reconegui que són documents amb ideologia i que tinguin mecanismes per reconèixer-la i interpretar-la.

\section{Bibliografia}

Cassany, D. (2008). Llegir críticament al llarg del currículum. Temps d'Educació, 34, pp. 7-10.

Da Silva, C.; Almeida, M.J. (1998). Condiçoes de produçao da leitura en aulas de física no ensino medio: um estudo de caso, a Almeida, M.J i Da Silva, C. (eds.). Linguagens, leituras e ensino da ciencias. Campinas: asociaçao de Leitura do Brasil.

Márquez, C.; Prat, A. (2005). Leer en clase de ciencias. Enseñanza de las Ciencias, 23 (3), pp. 431-440.

Oliveras, B.; Sanmartí, N. (2008). Análisis de una actividad orientada a promover la lectura crítica en clase de ciencias. XXIII Encuentros de Didáctica de las Ciencias Experimentales. Almeria.

Prat, A.; Márquez, C.; Marbà, A. (2008). Literacitat científica i lectura. Temps d'Educació, 34, pp 67-82. 